\title{
MORPHOLOGICAL HETEROGENEITY IN SOME ESTUARINE POPULATIONS OF THE CATFISH ARIUS JELLA (ARIIDAE) IN SRI LANKA
}

\author{
K. B. Suneetha Gunawickrama \\ Department of Zoology, Faculty of Science, University of Ruhuna, Matara, Sri Lanka \\ Accepted 25 November 2007
}

\begin{abstract}
Intra-specific morphological variation in the indigenous catfish Arius jella (Ariidae) was studied in five estuarine localities in Sri Lanka (Koggala lagoon, Walawe estuary, Garanduwa lagoon, Nilwala estuary and Chilaw lagoon) using morphometric analysis. Five morphometric characteristics describing the shape of the fish were significantly different among some of the locations. Significantly shorter pre-orbital length (8.3\% SL vs $9.2-10.7 \%$ SL in the other populations) in specimens from Walawe estuary is a populationspecific character. Significant differences in other characteristics were found indicating heterogeneity in morphology. The first two canonical variates (CV) explained $82.7 \%$ of the total variation in the data, yet the plot of the $\mathrm{CV}$ failed to display significant separation of the sample populations. Derived classification functions could correctly classify an average of less than $50 \%$ individuals into their a priori groups. There was no agreement on the isolation by distance model. The results indicate a small degree of spatial separation in morphology in A. jella among the studied estuarine localities.
\end{abstract}

Key Words: Estuarine Fish, Morphometrics, Partial Isolation, Spatial Separation, Population Structure

\section{INTRODUCTION}

Arius jella (Day 1877) (Syn. Pseudarius jella DAY) of the family Ariidae is an indigenous sea catfish widely distributed in the coastal areas and estuarine habitats of Sri Lanka (Munro, 1955). Being an important food fish, it supports subsistence fisheries in both lagoons and estuaries in Sri Lanka. In estuaries, it appears to have adapted an opportunistic feeding habit depending on the food source available, which includes fish eggs, shrimp larvae, and waste food from sewage (Suneetha, 1990). The species shows mouth-brooding of both fertilized eggs and newly hatched juveniles (personal observations). Differentiation of $A$. jella from the other Sri Lankan Ariidae is based largely on a handful of morphological characters (Jayaram, 1984 and Munro, 1955).

Palumbi (1994) described mechanisms that can lead to partial isolation and structuring of fish populations even in the marine environment, where an extensive opportunity for interchange of life-history stages exists. Accordingly, it can be hypothesized that such sub-structuring of populations may take place between geographically separated estuarine habitats such as lagoons and estuaries, which have open passage to the adjacent coast, year-round or periodically. In the face of extensive anthropogenic impact on the estuarine ichthyofauna, it is becoming increasingly important to investigate fish populations, their genetic and phenotypic variation, local adaptations, and population structure. Such knowledge is particularly valuable for exploitable species that require proper management for sustainable harvesting. Although A. jella is currently being exploited, such knowledge is non-existing for the species. The identification of phenotypically or genetically differentiated population units of exploitable species is a requirement in making conservation plans. Such insight is a prerequisite for the formulation of criteria for units of conservation in order to reduce the risk of extinction, particularly at the intra-specific levels. The existence of significant populationlevel differences have previously been noted in estuarine fishes using both morphological and genetic criteria (Roby et al., 1991 and Uiblein, 1995), providing evidence for the hypothesis of divergence due to partial isolation.

The present study seeks to elucidate the level of differentiation and associated spatial separation in populations of the small-eye

Author's email: suneetha@zoo.ruh.ac.lk 
catfish, A. jella, in five geographically separated estuarine localities along the southern and western coasts of Sri Lanka, using morphometric characters. It is hypothesized that the species may have maintained local genetic integrity in estuaries by minimizing its dispersal potential among adjacent estuaries so that phenotypic distinctiveness at a micro-geographic scale may exist among them.

\section{MATERIALS AND METHODS}

\section{Samples}

Five estuarine habitats including two estuaries and three lagoons along the southern and western coasts of Sri Lanka were selected for sampling: Koggala lagoon, Walawe estuary, Garanduwa lagoon, Nilwala estuary, and Chilaw lagoon (Fig. 1). Adult fish were collected using gill nets (mesh size 3.0-5.0 cm). A few samples were also collected from fishermen's catches. Fish were identified using taxonomic keys (Jayaram, 1984). Sex determination was made by observing gonads on dissection.

\section{Morphometric and Meristic data}

In addition to the standard length (SL) of individual fish, assessment of eight morphometric characters and eight meristic counts were selected for analysis (Table 1 and Fig. 2). Five of the meristic features (viz. number of spines in the dorsal, pectoral and pelvic fins, and number of rays in the dorsal and pelvic fins) had zero variation in data, and thus were removed from the analysis, leaving only three meristic counts warranting further analysis. Measurements were taken from the left side of individual fish, and were made by the same person to maximize consistency. As the caudal fins of some fish were damaged, standard length was chosen to represent size. Measurements were made to the nearest $0.01 \mathrm{~cm}$ using Vernier calipers. All length measurements were taken between identified points along the anteriorposterior axis, whereas depth measurements of the head and body were taken perpendicularly between the identified points (Fig. 2). Each count was taken twice on the same specimen using a hand-held magnifying lens. Abbreviations of measurements used in the text are listed in Table 1.

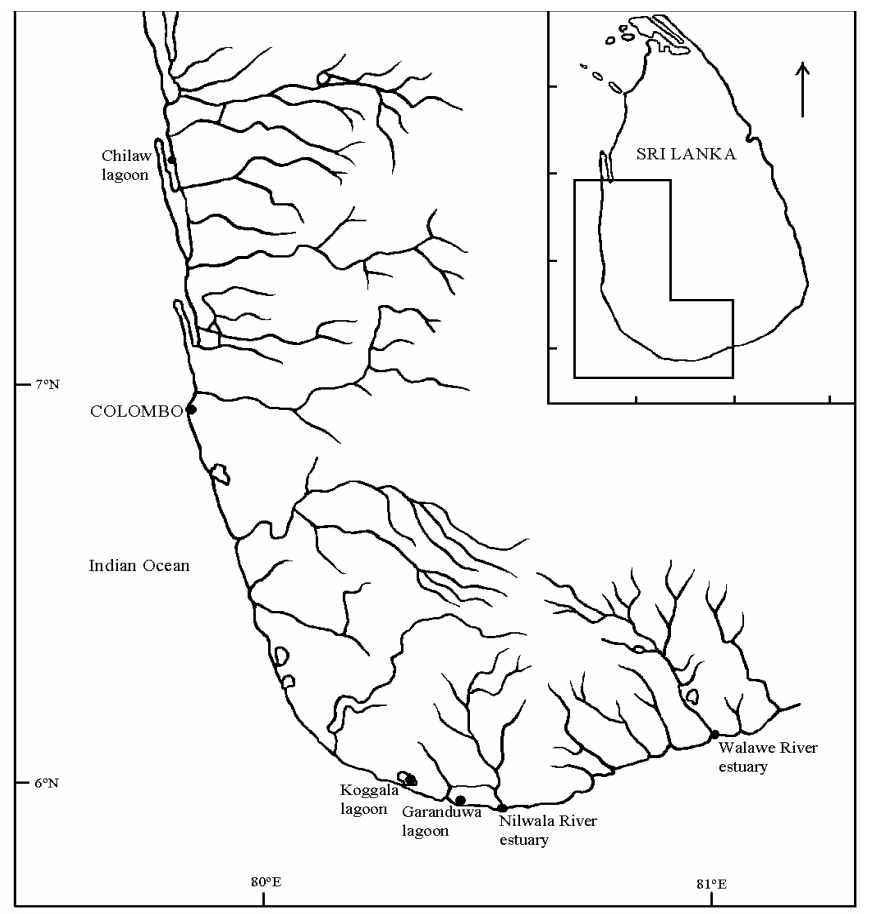

Figure 1. Map showing the collection localities of Arius jella. 
Table 1. Morphometric and meristic characteristics of Arius jella collected during the study.

\begin{tabular}{|c|c|c|c|}
\hline Character & & Description & ${ }^{\mathrm{a}}$ code \\
\hline \multicolumn{4}{|l|}{ Morphometrics } \\
\hline Standard length & $S L$ & snout tip to the mid-point of hypural base & $1-7$ \\
\hline Head length & $H L$ & snout tip to the posterior edge of operculum & $1-5$ \\
\hline Orbital diameter & $O L$ & horizontal width of the orbit & $2-3$ \\
\hline Snout length & PROL & snout tip to anterior margin of orbit & $1-2$ \\
\hline Post-orbital length & PsOL & posterior edge of orbit to edge of operculum & $3-5$ \\
\hline Head depth & $H D$ & maximum depth of head & ${ }^{b} 4-8$ \\
\hline Body depth & $B D$ & maximum depth of body & $6-9$ \\
\hline Caudal peduncle length & $C P L$ & base of last anal ray to base of hypural complex & $7-10$ \\
\hline Pre-dorsal length & PRDL & snout tip to the origin of dorsal fin & $1-6$ \\
\hline \multicolumn{4}{|l|}{ Meristics } \\
\hline Number of gill-rakers & $G R$ & gill-rakers on the second left gill arch & \\
\hline Rays- caudal fin & $C F R$ & number of rays in the caudal fin & \\
\hline Rays- pectoral fin & $P C R$ & number of rays in the pectoral fin & \\
\hline
\end{tabular}

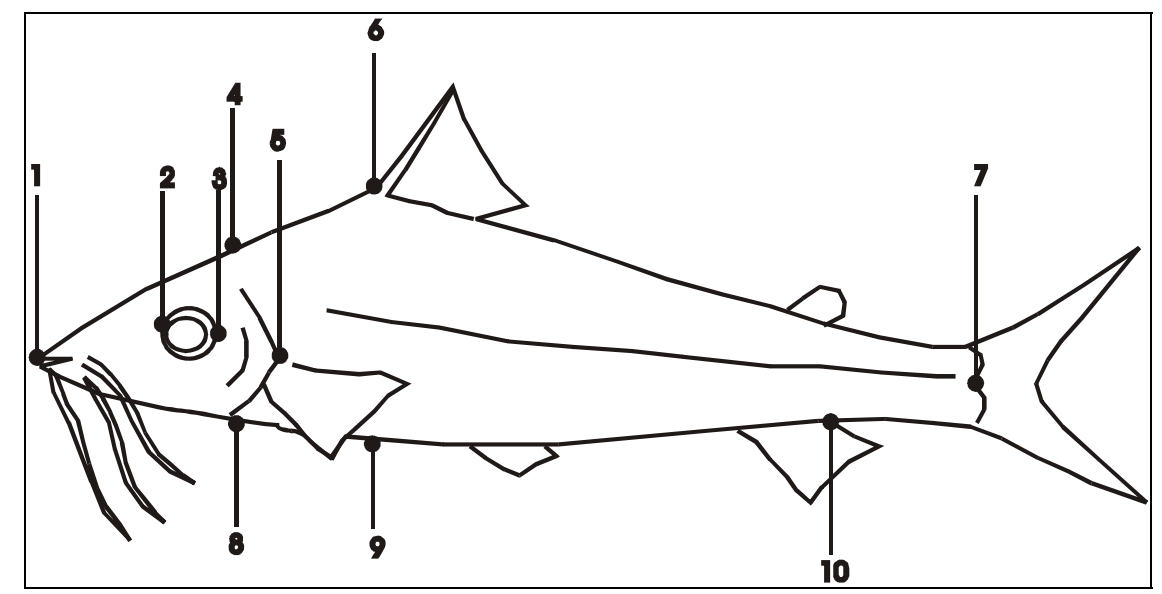

Figure 2. Schematic diagram of fish showing superficial landmark points used in measuring morphometric characters of Arius jella, listed in Table 2.

\section{Data and statistical analysis}

Sexual dimorphism in morphological characters was tested prior to data analysis using one-way ANOVA to decide whether to consider the sex of specimens as an independent factor in the analysis. Measurements taken on fish would show a strong correlation for the size of fish under allometric growth (Reist, 1985, 1986). Accordingly, comparison of morphometric data among different groups should be preceded by a suitable correction to remove size-effect. Many Ariid catfishes show allometric growth (Darracott, 1977). All individual morphometric data were thus corrected, using the following equation (Elliott et al., 1995).

$$
\mathrm{M}_{\mathrm{S}}=\mathrm{M}_{\mathrm{O}}\left(\mathrm{L}_{\mathrm{S}} / \mathrm{SL}\right)^{b}
$$


Working formula for each specimen for a given morphometric character is,

$$
\log _{10} \mathrm{M}_{\mathrm{S}}=\log _{10} \mathrm{M}_{\mathrm{O}}+b \log _{10} \mathrm{~L}_{\mathrm{S}}-b \log _{10} \mathrm{SL}
$$

where $M_{S}$ is the standardized character measurement, $\mathrm{M}_{\mathrm{O}}$ is the observed character measurement, $\mathrm{L}_{\mathrm{S}}$ is the mean standard length for all fish from five collections, SL is the standard length of the specimen, and $b$ is the slope of the regression of $\log _{10} \mathrm{M}_{\mathrm{O}}$ on $\log _{10}$ SL for all fish. The standardized data were rechecked by correlation against size to see whether the size dependence had been removed. The standardized data were used in all statistical analysis.

Standardized data were analyzed by univariate and multivariate methods. Differences among geographic samples were tested by oneway analysis of variance (ANOVA) followed by Tukey HSD multiple comparison test for unequal sample sizes (Zar, 1984). Tests were considered significant at $\mathrm{P}=0.05$. Raw meristic counts with observable variation within samples were compared using Kruskal-Wallis nonparametric test considering the difference in the median as well as the distribution. Forward stepwise Discriminant Function Analysis (DFA) on morphometrics was performed to identify the characteristics that were important in distinguishing population groups in the pooled sample. Classification functions from those morphometric measures were formulated for each location to determine the group to which each case most likely belonged. Based on these functions, DFA reclassifies individual fish into groups, which are then compared with the $a$ priori group of that individual to get the percentage of classification success. Pair-wise squared Mahalanobis distance $\left(D^{2}\right)$ among samples were calculated and tested for their significance (Mais, 1972). Pair-wise geographical distance was tested for correlation with the pair-wise $D^{2}$ to check for agreement to the model of isolation by distance (Slatkin, 1993). All data and statistical analyses were carried out using the software package STATISTICA v 7·0 (Statsoft, USA).

\section{RESULTS}

The details of size of adults of $A$. jella collected during the study are given Table 2 . None of the morphometric characters recorded was significantly different between males and females, and thus the data analysis was done without considering the sex of the individuals. The sex ratio (male: female) in the pooled sample was 5.5:1, and the sex ratio in individual samples was also male biased.

Mean standard length of $A$. jella collected was $19.45 \pm 4.43 \mathrm{~cm}$. Significant heterogeneity in size was found among the samples, and the fish from Nilwala estuary were of the largest size (Tukey HSD Post Hoc Test, $p<0.001$ ). Univariate ANOVA revealed significant differences in five of the size-corrected morphometric measures of fish among some of the estuaries $(p<0.05)$, ie. head length (HL), snout length (pre-orbital length, PROL), postorbital length (PsOL), head depth (HD) and body depth (BD) (Table 3). HL was significantly greater in the fish in Garanduwa lagoon than those in other locations, except Koggala lagoon. Significantly shorter PROL is a populationspecific characteristic of fish in the Walawe estuary. Heterogeneity in the other significant characters did not show any population-specific variation. Meristic counts were relatively homogeneous among the samples although slight, yet non-significant variation in the distribution was apparent in the number of gill rakers (GR), number of rays in the caudal fin $(\mathrm{CF}-\mathrm{R})$ and number of rays in the pectoral fin (PCF-R) (Table 3).

Table 2. Collection localities, composition and size statistics (based on the standard length) of adult Arius jella.

\begin{tabular}{|c|c|c|c|c|c|c|}
\hline \multirow[t]{2}{*}{ Location } & \multirow[t]{2}{*}{ Estuary type } & \multicolumn{2}{|c|}{$\mathrm{N}$} & \multirow[t]{2}{*}{ Size Range $(\mathrm{cm})$} & \multirow[t]{2}{*}{ Mean } & \multirow[t]{2}{*}{ SD } \\
\hline & & Male & Female & & & \\
\hline L1: Koggala lagoon & Coastal lagoon & 35 & 02 & $12.31-26.62$ & 17.66 & 2.95 \\
\hline L2: Walawe estuary & Riverine estuary & 34 & 03 & $11.62-25.21$ & 17.64 & 3.29 \\
\hline L3: Garanduwa lagoon & Coastal lagoon & 36 & 06 & $15.83-25.11$ & 17.42 & 1.96 \\
\hline L4: Nilwala estuary & Riverine estuary & 29 & 04 & $23.20-32.42$ & 26.90 & 2.59 \\
\hline L5: Chilaw lagoon & Coastal lagoon & 22 & 13 & $14.71-27.11$ & 18.69 & 2.67 \\
\hline
\end{tabular}


Derived discriminant functions in DFA using eight of the size-corrected morphometric characters identified PROL, HD, HL and PsOL as significant contributors, in order of importance (Wilk's Lambda $=0.58$, approx. $\mathrm{F}_{(28}$, $\left.{ }_{596)}=3.50, \mathrm{p}<0.001\right)$, while caudal peduncle length (CPL), BD and orbital diameter (OL) were not significant, and pre-dorsal length (PRDL) was not in the model. Among the four characters that were found to be useful in population differentiation, PROL was the most significant contributor. As revealed by the respective eigen-values, the first two canonical variables (CV) accounted for $82.7 \%$ (CV1: $53.6 \%$ and CV2: $29.1 \%$ ) of the total variance in the data. Examination of the correlations revealed that $\mathrm{HD}, \mathrm{HL}$, and $\mathrm{PsOL}$ contributed mostly to CV1 and hence, accounted mostly for the variance in the data, whereas PROL contributed mostly to CV2. The derived classification functions could correctly classify only an average of $45.8 \%$ individuals into their $a$ priori groups, indicating that the observed morphological variation alone cannot differentiate the studied populations. While the best classification success was observed for the fish from Garanduwa lagoon (52.5\%), the lowest success was for the fish from Koggala lagoon $(35.3 \%)$, whereas those for the Walawe estuary, Nilwala estuary, and Chilaw lagoon were 51.4\%, $39.4 \%$, and $48.6 \%$ respectively. All pair-wise Mahalanobis distance $\left(D^{2}\right)$ values except that between Nilwala estuary and Chilaw lagoon were significant $(<0.05-<0.001)$, yet $D^{2}$ values were not significantly correlated to the approximate pair-wise geographic distance values $(p>0.05)$. The plot of first two canonical variables failed to show significant separation of samples with group means located close to each other with $95 \%$ confidence ellipses for the five estuarine samples overlapping greatly (Fig. 3).

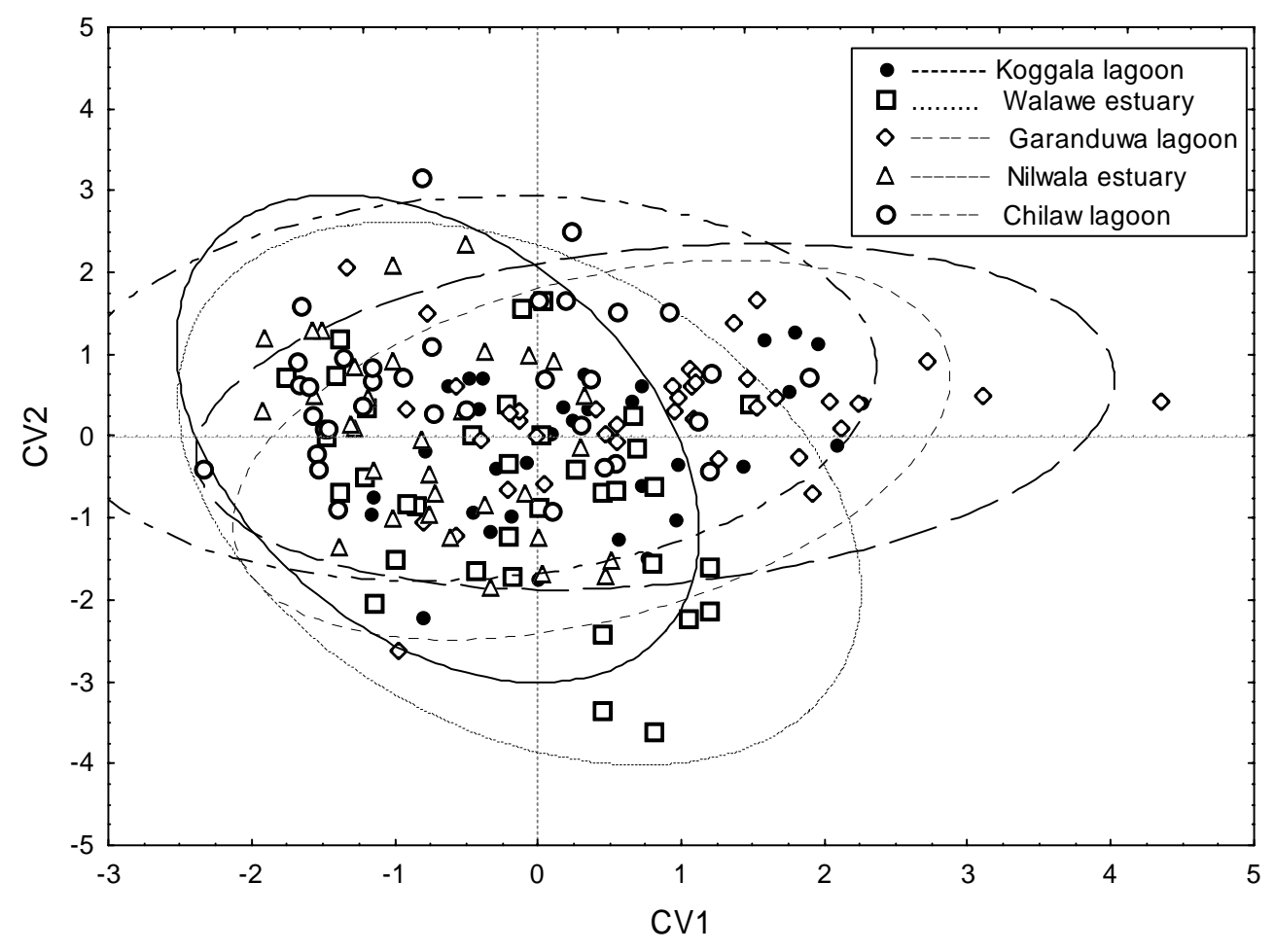

Figure 3. Plot of first and second canonical variate (CV) scores for the five collection sites of Arius jella with 95\% confidence ellipses. HD, HL and PsOL mostly contributed to the CV1, which explains $53.6 \%$ of the variation. CV2 is most heavily weighted by PROL, and explains $29.1 \%$ of the variation. 

Table 3. Summary of morphometric (as \%SL, mean \pm SD) and meristics characteristics of Arius jella.

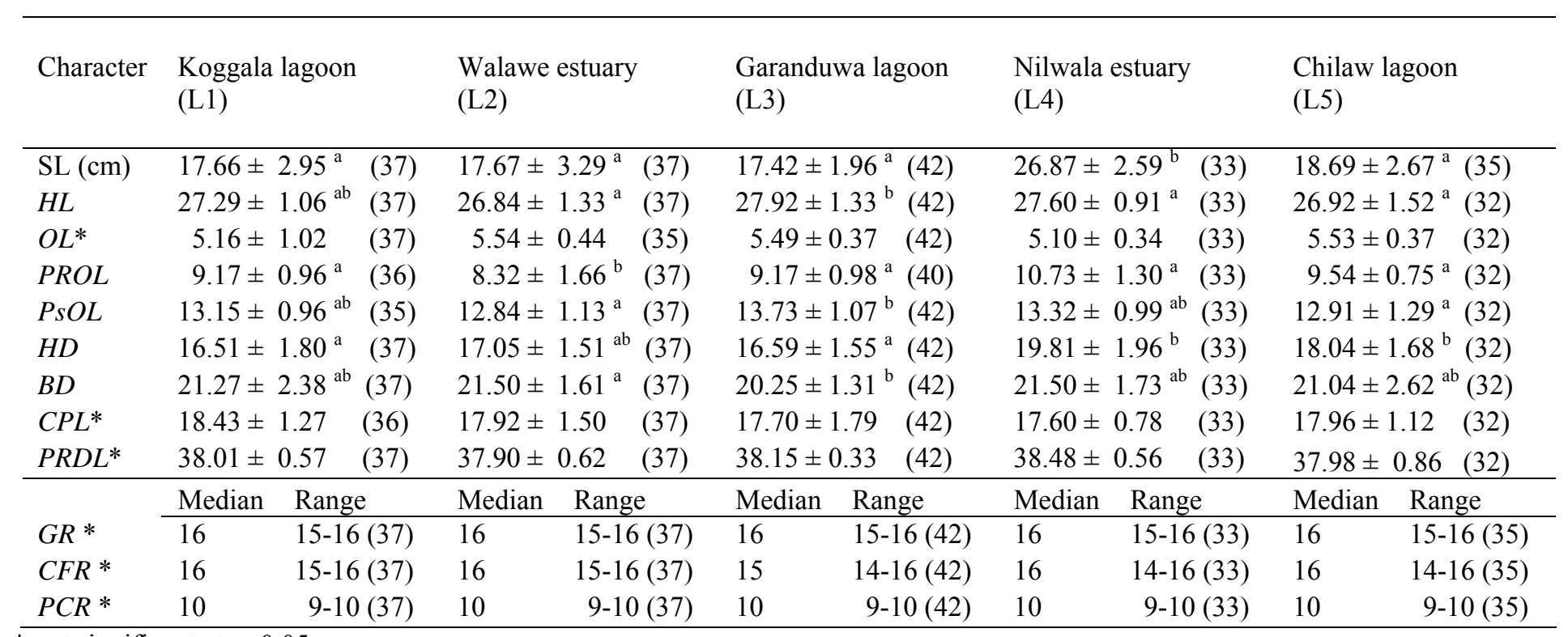

* not significant at $\mathrm{p}<0.05$

Superscript letters indicate test results of the ANOVA on size-corrected characters, followed by Tukey HSD (for unequal N) post-hoc comparison tests. Different superscript letters in each row indicate statistically significant differences $(\mathrm{p}<0.05)$ among locations. Sample size is given within brackets 


\section{DISCUSSION}

Significant spatial heterogeneity in morphology of Arius jella among some estuarine localities is evident from the present study. As some of the selected estuaries were located close to each other (15-20 km apart), exceptional intra-specific morphological variation is not expected under the isolation by distance model. As the data were not in agreement with the model, it appears that the variation in morphology has occurred in the populations in response to other factors that lead to spatial divergence.

Some of the morphological characters of the fish were useful in generating the heterogeneity in morphology. According to the DFA, these include snout length (PROL), head depth, head length and post-orbital length. Shorter PROL on average was found to be an indicator to distinguish fish samples of Walawe estuary from all others. The rest of the morphometrics also contributed significantly to heterogeneity but were not good identifiers of individual populations. According to the findings, none of the meristic characters showed significant heterogeneity in A. jella.

Morphological measurements have been widely used to differentiate various fish populations (Elliott et al., 1995; Uiblein, 1995; Hurlbut \& Clay, 1998). Among the vertebrates, phenotypic variability is considered to be greatest in fish, which have relatively higher within-population coefficients of variation of phenotypes (Carvalho, 1993). This variability is likely to have arisen from the great phenotypic plasticity of fishes in response to changes in environmental factors (Wimberger, 1991, 1992). The present study did not include a synthesis of environmental parameters among the estuaries. However, it is well known that the estuarine environments undergo great fluctuations in physico-chemical conditions as they are under the heavy influence of tidal fluctuations and fresh water influx mainly from rainfall. Under such variability in the environment, maintenance of distinctive phenotypes might be impractical. However, accumulated phenotypic differences can be further enhanced by minimizing exchange among estuarine population units. Most estuarine habitats have an open seawater connection periodically in response to tidal fluctuations, and the extent of freshwater influx varies accordingly. Some estuaries undergo prolonged closure of the seaward opening. When there is an open passage at the estuarine mouth, drift-vulnerable life stages such as pelagic eggs and larvae may drift with the tidal current lagoon-ward or ocean-ward creating many opportunities for the fish stocks in estuaries to interchange via coastal currents. If such an intermixing occurs, it is highly unlikely to result in genotypic or phenotypic distinctiveness among various estuarine populations of fish. Even with a great potential for indiscriminate dispersal, some fishes may have adapted to remain within their habitats, allowing development of locally adapted stocks.

Arius jella is considered a common saltwater dispersant in coastal waters of Sri Lanka, including estuaries and lagoons. Present records on the availability and abundance of the species indicate widespread dispersal ability (personal unpublished data). However, some of its life history features may pose some limitation on indiscriminate dispersal. Mouth brooding and caring for the young is known among catfishes (Ochi et al., 2001). Sexually mature females of A. jella produce large eggs, and they mouth brood both fertilized eggs and larvae (personal observations). This type of life strategy can be expected to pose some restriction on the dispersal of early life history stages among coastal populations. However, lack of large phenotypic differences among populations as revealed in the present study indicates that any restriction on gene flow that may occur on these population units is not sufficient to maintain them in complete isolation. Further studies on distribution and life history of the species will be useful to confirm this aspect.

Overall, the results indicate that significant heterogeneity in morphology exist among some of the studied estuarine populations of A. jella. Observed morphological variation may have occurred due to factors such as partial isolation of the populations and local adaptations. Genotypic variability should also be studied to see whether the observed phenotypic heterogeneity has a genetic basis, or whether this is merely phenotypic plasticity resulting from environmental variability. Compatible results from both morphological and genetic analyses will reveal a convincing stock structure of the species among coastal wetlands in Sri Lanka. If populations remain isolated from each other on an evolutionary time scale, resulting in a distinguishable divergence phenotypically and genetically, they could be considered evolutionarily significant units (ESUs). If isolation continues, these units may evolve into reproductively isolated populations and lead to 
allopatric speciation. Accordingly, when conservation priorities are laid down, such intraspecific units must be considered as units of conservation, not just the species as a whole, to preserve adaptive traits. Although the populations of $A$. jella as revealed by the present study are not completely spatially isolated at present, this may be of evolutionary significance with respect to long-term divergence. Studies on existing variation in phenotypic and genotypic characters of the species are of great importance in making conservation plans for exploitable species such as A. jella.

\section{ACKNOWLEDGEMENTS}

The study was funded by a research grant (RU/SF/RP/2001/03) from the University of Ruhuna. Technical assistance was provided by Ms. J.L.P.S.S. Jayasekara. Comments made by two anonymous referees are gratefully appreciated.

\section{REFERENCES}

Carvalho, G. R. (1993). Evolutionary aspects of fish distribution: genetic variability and adaptation. Journal of Fish Biology 43 (Supplement A): 53-73.

Darracott, A. (1977). Availability, morphometry, feeding and breeding activity in a multispecies, demersal fish stock of the western Indian Ocean. Journal of Fish Biology 10: 1-16.

Elliott, N. G., Haskard, K. \& Koslow J. A. (1995). Morphometric analysis of Orange roughy (Haplostethus atlanticus) off the continental slope of southern Australia. Journal of Fish Biology 46: 202-220.

Hurlbut, T. \& Clay, D. (1998). Morphometric and meristic differences Between shallow and deepwater populations of whitehake (Urophycis tenuis) in the southern Gulf of St. Lawrence. Canadian Journal of Fisheries and Aquatic Sciences 55: 2274-2282.

Jayaram, K.C. (1984). Ariidae. In: Fischer W. and Bianchi G. (Eds.), FAO identification sheets for fishery purposes. Western Indian Ocean Fishing area 51..1. FAO, Rome.

Mais, K.F. (1972). A subpopulation study of the Pacific sardine. Californian Fish and Games 58: 296-314.
Munro I.S.R. (1955). The Marine and freshwater fishes of Ceylon. Department of External Affairs, Canberra, Australia. 351 pp.

Ochi, H., Kanda, T. \& Yanagisawa, Y. (2001). Nest building and brooding behaviour of the bagrid catfish Auchenoglanis occidentalis (Valenciennes, 1840) in lake Tanganika. Copeia 2: $566-570$.

Palumbi, S. R. (1994). Genetic divergence, reproductive isolation and marine speciation. Annual Review of Ecology and Systematics 25: 547-572.

Reist, J. D. (1985). An empirical evaluation of several univariate methods that adjust for size variation in morphometric data. Canadian Journal of Zoology 63: 1429-1439.

Reist, J. D. (1986). An empirical evaluation of coefficients used in residual and allometric adjustment of size covariation. Canadian Journal of Zoology 64: 1363-1368.

Roby D, Lambert J.D, Sevigny J.M (1991). Morphometric and electrophoretic approaches to discrimination of Capelin (Mallotus villosus) populations in the estuary and Gulf of St. Lawrence. Canadian Journal of Fisheries and Aquatic Science 48: 2040-2050.

Slatkin M. (1993). Isolation by distance in equilibrium and non-equilibrium populations. Evolution 47: 264-279.

Uiblein F. (1995). Morphological variability between populations of Neobythites (Pisces: Ophididae) from the deep Red Sea and the Gulf of Aden. Marine Ecology Progress Series 124: 23-29.

Wimberger, P. H. (1991). Plasticity of jaw and skull morphology in the neotropical cichlids Geophagus brasiliensis and G. steindachneri. Evolution 45: 1545-1561.

Wimberger, P. H. (1992). Plasticity of fish body shape. The effects of diet,development, family and age in two species of Geophagus (Pisces: Cichlidae).Biological Journal of the Linnaean Society 45: 197-218.

Zar, J. H. (1984). Biostatistical Analysis (Second Edition). New Jersey: Prentice-Hall. 